\title{
A CDMA-Based Soil-Quality Monitoring System for Mineland Reclamation
}

\author{
Dongxian $\mathrm{He}^{1}$, Daoliang $\mathrm{Li}^{2}$, Jie $\mathrm{Bao}^{3}$, and Shaokun $\mathrm{Lu}^{1}$ \\ ${ }^{1}$ Key Lab. of Agriculture Engineering in Structure and Environment, \\ College of Water Conservation and Civil Engineering, China Agricultural University, \\ Beijing, P.R. China \\ ${ }^{2}$ College of Information \& Electrical Engineering, \\ China Agricultural University, \\ Beijing, P.R. China \\ ${ }^{3}$ College of Engineering, China Agricultural University, \\ Beijing, P.R. China \\ he_dongxian@hotmail.com
}

\begin{abstract}
After the mining of mineral resource, mineland resources utilization became increasingly complicated. Soil and planting information can be used as the indicators to evaluate mineland reclamation level. In order to obtain the soil and planting information in real time, a CDMA-based soil-quality monitoring system was developed to wirelessly monitor air/soil environment and plant image in remote or local area. As a system test, a monitoring system equipping one network camera and four sensors including air temperature, relative humidity, soil temperature, and soil water content was deployed at a national mineland reclamation demonstration in Fuxin, Liaoning and communicated with a remote server in Beijing using CDMA service with IPsec-based VPN connection. Via a one-year testing, the CDMA-based soil-quality monitoring system as a dynamic infrastructure and available tool showed a good performance for mineland reclamation quality evaluate.
\end{abstract}

Keywords: CDMA service, Mineland reclamation quality evaluate, Soil water content, VPN connection.

\section{Introduction}

After the mining of mineral resource, mineland resources utilization became increasingly complicated. In order to obtain the mineland detail information in real time for the reclamation in land administrative department of mining enterprise concerned, soil and planting information changes of mineland area is very important and can be used as the indicators to evaluate mineland reclamation level. How to get the indicator information and how to sign the reclamation quality is concerned to sustainable development of mineland reclamation utilization. Therefore, efficiency and low cost way to get mineland reclamation quality change is essential and required for mining enterprise and land administrative department.

Mining land reclamation by the quality indicator technology developed in recent decade is based on wireless network technology, GIS, and remote sensing technology 
can be used as the integration charge of indicators of reclamation quality index. In the past 10 years, mineland reclamation in the quality indicator technology has carried out a significant development and has achieved remarkable achievements [1-8]. Therefore, development of a dynamic monitoring system of mineland reclamation for obtaining the soil and planting information in an efficiency and low cost way is becoming required and becoming more important.

\section{Materials and Method}

\subsection{System Configuration}

The CDMA-based soil-quality monitoring system consists of a CDMA module with IPsec-based VPN function (InRouter210C, Beijing Inhand Co., China), a network bullet camera (IP7330, Vivotek Co., Taiwan), a web-server-embedded chip (PICNIC2.0, TriState Co., Japan), switching hub (TL-SF1005D, TP-Link Tech. Co., China), a sensor module, and a solar power supply module (SPV-DCRC-20W, Beijing Sangpu Co., China) (Fig. 1). The sensor module is including temperature (PT1000, Hayashi Elect. Co., Japan), relative humidity (CHS-UPS, TDK Co., Japan), soil temperature (PT1000, Hayashi Elect. Co., Japan) and soil water content (EC-5, Decagon Co., US). The power supply module consists of a power control device, two 20W monocrystalline silicon photovoltaic panels, a 75AH battery (LC-X1275ST 75AH, Panasonic Co. Japan), and a timer (ZN48T-12V, Symore Co. China). The realtime data and images collected by the sensors and network camera are dynamically and wirelessly transported to a remote server via TCP/IP. The CDMA-based soilquality monitoring system was operated between appointed duration by a timer.

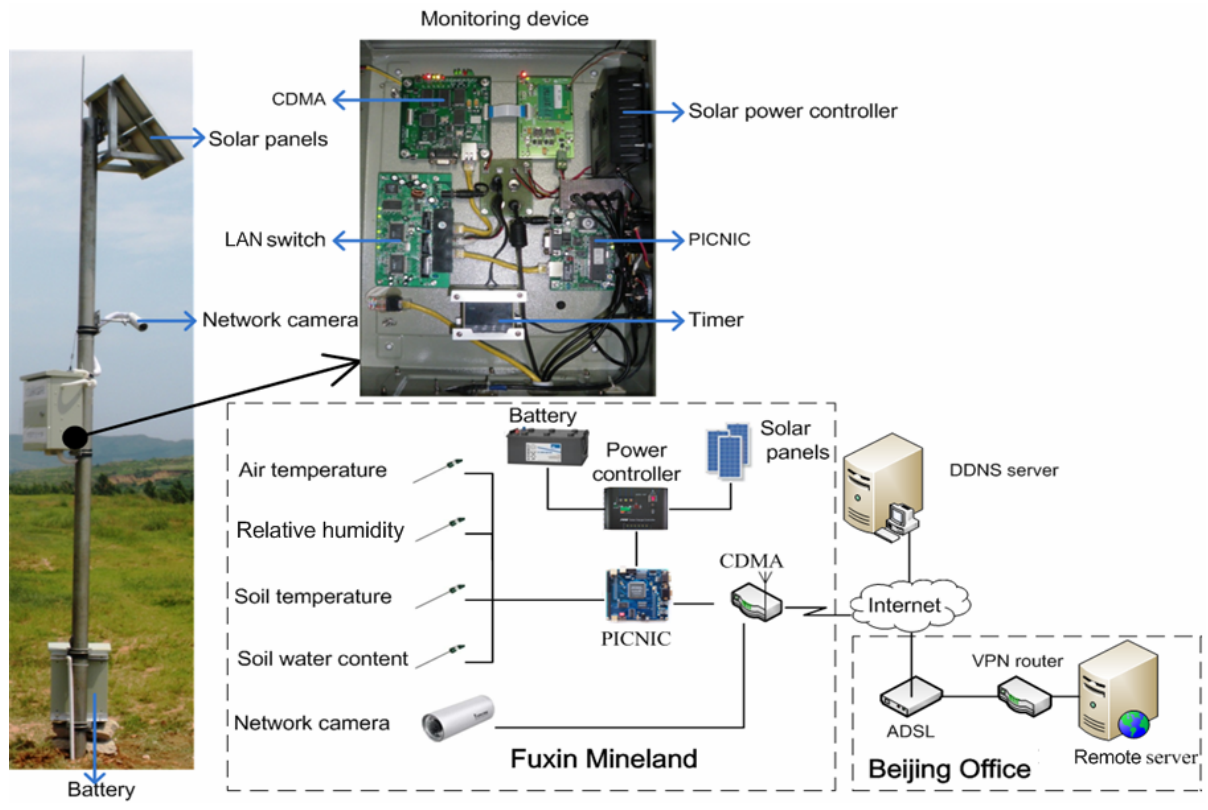

Fig. 1. The CDMA-based soil-quality monitoring system 


\subsection{Topological Architecture}

Each CDMA-based soil-quality monitoring system as an isolated local area network is connected to Internet via CDMA service by Telecom China (Fig. 1). That means the monitoring system as a sensing network node can be constructed to a large-scale wireless sensing network under CDMA signal covered areas. The monitoring system is also easy to increase sensor channels and network cameras as well as the CDMA bandwidth depending. In this monitoring system, four sensor channels were integrated into the webserver-embedded chip within one LAN IP and each camera has a LAN IP. All data and images are communicated by dynamic HTTP file and identified dynamically and storied by one to five remote servers. The CDMA module will be dynamically connected to the remote servers via IPsec-based VPN security technology. In order to identify the specified the remote servers, the remote VPN routers have to use a dynamic domain connection or a fixed global IP to support the remote VPN calling. The monitoring systems deployed anywhere will become to a local network connection because of the IPsec-based VPN tunnels connected. Therefore, all accredited users or clients can visit or manage the wireless sensing devices anywhere and anytime under Internet environment.

\subsection{Testing Environment}

A CDMA-based soil-quality monitoring system was deployed in a national mineland reclamation demonstration zones in Fuxin, Liaoning province for obtaining air and soil environment, and plant images. In this testing, one remote server with IPsec-based VPN router (BV-601, Nesco Co., China) is deployed in China Agricultural University located in Beijing, China. The testing experiments were conducted for one year.

\section{Results and Discussion}

\subsection{Dynamic Image Transportation}

A Java applet program was installed in the remote server to download image from the network camera via HTTP every minute and stored in the remote server. In order to monitor more areas, the network camera has setup in two benchmark level for measuring height of plants and leaf area index (Fig. 2). The image processing results

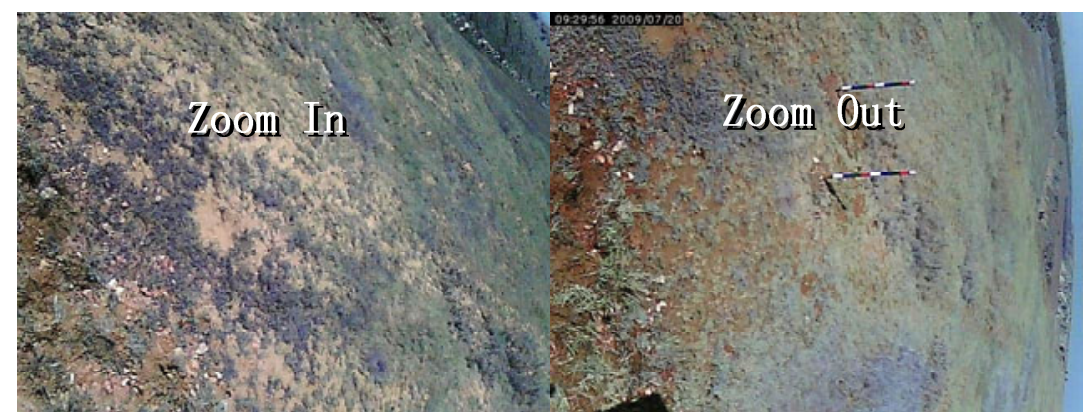

Fig. 2. The dynamic images obtained by the CDMA-based soil-quality monitoring system 
will be described by other papers and omitted in this paper. All accredited users can visit or manage the network camera modules and any clients can visit the real-time or historical images from website anywhere and anytime under Internet environment. Therefore, this network camera module with an enough-quality dynamic image requirement at low cost is suitable to the monitoring system.

\subsection{Dynamic Environment Data Transportation}

The environmental data such as temperature, relative humidity, soil temperature, and soil water content were dynamically storied or issued in webpage or Extensible Markup Language (XML) file by a special JAVA applet program in the remote servers (Fig. 3). The 10-bit analog signals of the sensors were obtained by the webserver-embedded chip without any memory and firmware. Therefore, the legacy problem of the USB-based or RS232-based devices caused from the firmware update can be solved in this monitoring system. The environmental data were also used to combine with image processing results such as the shape and color features to construct an artificial neural network model based on back-propagation algorism for identifying the growth measurement and nutrition detection. The sensor module is easy to increase the sensor channels with a little influence in data communication, because the narrow CDMA bandwidth will strongly influence the image communication in this monitoring system.

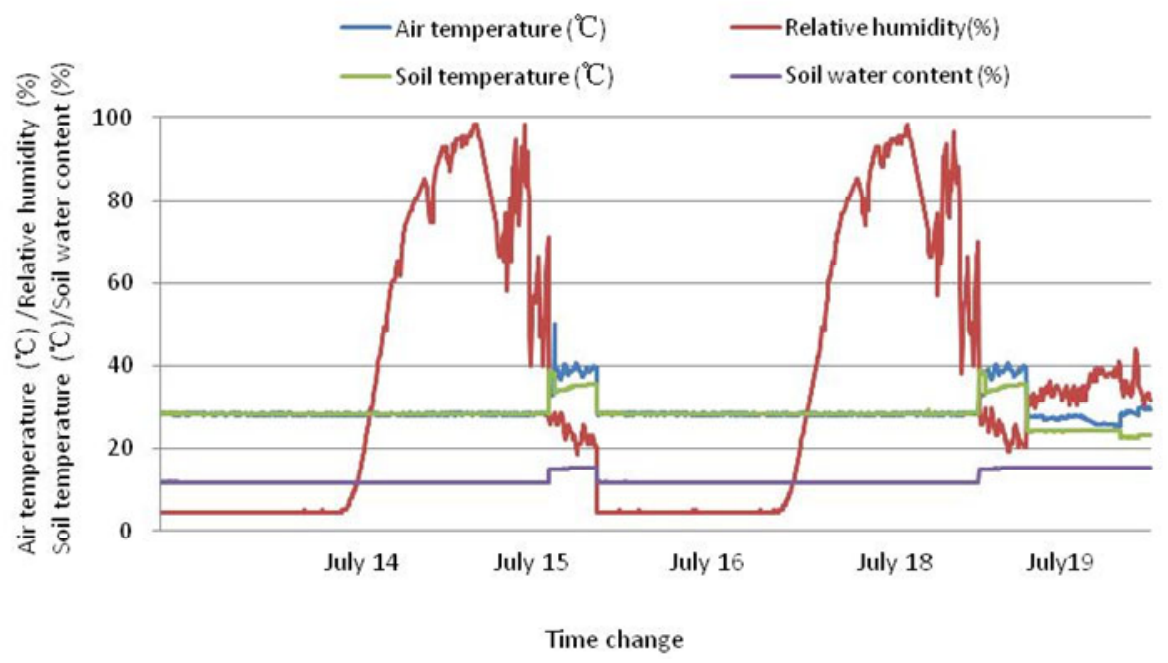

Fig. 3. Environmental data measured by the CDMA-based soil-quality monitoring system

\subsection{Network Communication and Electronic Consumption}

The monitoring system were communicated with the remote server in Beijing by a 20-30 Kbps access speed with over 25-27 signal quality level of CDMA services. The real-time image with $640 * 480$ pixels resolution captured by the network camera and 
compressed to JPEG file were dynamically transported to remote server during the system operation. The all data and images obtained at same time were identified by IP which is transferred to take turns and with omitted disconnecting IP. In this case, less than $2 \%$ of packet loss rate was resulted. Local user can visit the remote server via LAN, remote users can visit the remote server through Internet. These two methods have nothing to do with the CDMA. Therefore, remote user access speed is limited by the bandwidth of Internet hotspot such as ADSL network in this case. The remote server can support simultaneous accesses of 20 remote users. However, the numbers of concurrent local users do not have measurements and no restrictions on.

The monitoring system using $12 \mathrm{~V}$ DC power supply and timed operation by solar supply system consisting of two $20 \mathrm{~W}$ solar panels and a $75 \mathrm{Ah}$ battery were consumed about $22 \mathrm{~W}$ capacity with $1.8 \mathrm{~A}$ electric current. This power supply module can drive the monitoring system for about 10 hours in sunshine day and for about 5 hours in cloudy day. Therefore, four hours operation divided to two hours in morning or afternoon were connected in this system testing.

\section{Conclusion}

The real-time environment data and images were dynamically collected in remote area by the CDMA-based soil-quality monitoring system. This CDMA-based soilquality monitoring system based on web-server-embedded technology and CDMA service with IPsec-based VPN function as a node infrastructure is useful to construct a ubiquitous wireless sensing network in high-security for mineland reclamation.

\section{Acknowledgments}

This work has been supported by International Technology Cooperation Program (2007DFA91050).

\section{References}

1. Bradshaw, A.: The use of natural processes in reclamation - advantages and difficulties. Lands. Urb. Plan. 51, 89-100 (2000)

2. He, D.X., Hirafuji, M., Fukastu, H., Yang, Q.: An environmental measurement system using wireless networks and web-server-embedded technology. In: Progress of Information Technology in Agriculture, pp. 541-545. China Agriculture Press, Beijing (2003)

3. Chena, J.C., Changb, N.B., Shieh, W.K.: Assessing wastewater reclamation potential by neural network model. Eng. Appl. Artif. Intell. 16, 149-157 (2003)

4. Fukatsu, T., Hirafuji, M.: Field monitoring using sensor-nodes with a web server. J. Robot. Mechatron. 17, 164-172 (2005)

5. Sevkiye, S.T.: An analysis on the efficient applicability of the land readjustment (LR) method in Turkey. Habitat. Int. 31, 53-64 (2007) 
6. Anderson, J.D., Ingram, L.J., Stahl, P.D.: Influence of reclamation management practices on microbial biomass carbon and soil organic carbon accumulation in semiarid mined lands of Wyoming. Appl. Soil Ecol. 40, 387-397 (2008)

7. Philip, A.T., Helmers, D.P., Kingdon, C.C., McNeil, B.E., de Beurs, K.M., Eshleman, K.N.: Changes in the extent of surface mining and reclamation in the central appalachians detected using a 1976-2006 Landsat time series. Remote Sens. Environ. 113, 62-72 (2009)

8. Li, F.H., Keren, R.: Calcareous sodic soil reclamation as affected by corn stalk application and incubation: a laboratory study. Soil Sci. Soc. Chin. 19, 465-475 (2009) 